\title{
AVALIAÇÃO DA INIBIÇÃO DA INCRUSTAÇÃO DE FOSFONATADOS: EFEITO DO TEMPO E TEMPERATURA
}

\author{
B. T. C. BEZERRA, S. M. P. LUCENA, I. J. SILVA Jr*. \\ Universidade Federal do Ceará, Departamento de Engenharia Química \\ *e-mail: ivanildo@gpsa.ufc.br
}

\begin{abstract}
RESUMO
Os métodos existentes para medir a inibição da incrustação de $\mathrm{CaCO}_{3}$ proveniente da água utilizada em processos industriais e para fins domésticos baseiam-se em medidas indiretas, seja através de ensaios eletroquímicos ou não. Para a classe de inibidores fosfonatados a capacidade de adsorver na semente do cristal de $\mathrm{CaCO}_{3}$ é crucial para sua efetividade. Neste estudo propomos um método de adsorção em batelada com uso de calcita da Islândia (Iceland spar) como material padrão para determinação da capacidade anti-incrustante do composto fosfonatado ácido nitrilotrimetilfosfônico (ATMP). O método tem a vantagem de ser rápido e simples e apresentar boa reprodutibilidade. A concentração de ATMP foi determinada a partir da análise da quantidade de fósforo em solução empregando-se a técnica de Espectroscopia de Emissão Ótica com Plasma Indutivamente Acoplado (ICP-OES). O aumento da temperatura de $25^{\circ} \mathrm{C}$ para $70{ }^{\circ} \mathrm{C}$ provocou um aumento na retenção do inibidor de 4,5 vezes. $\mathrm{O}$ tempo de contato aumentou a retenção do inibidor na superfície da calcita. $\mathrm{O}$ ensaio proposto também mostrou ótima correlação com composto fosfonatado ensaiado por método eletroquímico.
\end{abstract}

\section{INTRODUÇÃO}

O depósito de incrustações inorgânicas, principalmente do $\mathrm{CaCO}_{3}$, em equipamentos industriais tem se tornado um problema recorrente.

Essas incrustações tratam-se de sólidos inorgânicos que precipitam a partir da água em decorrência principalmente da presença de sulfatos e carbonatos de cálcio e magnésio. Esses depósitos de sal limitam a troca térmica em equipamentos, uma vez que passam a apresentar propriedades semelhantes à de um isolante térmico.

Nos últimos 30 anos, muitos trabalhos foram realizados com o intuito de desenvolver produtos químicos que pudessem prevenir ou retardar a formação de incrustações minerais. Tais pesquisas resultaram em uma gama de inibidores que podem ser implantados para gerenciar e controlar tais incrustações, de acordo com o seu tipo e condições em que se formam (BELLARDY, 2009).

Industrialmente, os inibidores mais empregados são, geralmente, compostos derivados de três grupos químicos: polifosfatos, ácidos policarboxílicos e polifosfonatos (KETRANE et al., 2009).

A ação desses produtos está fundamentada na adsorção dos mesmos sob a superfície do precipitado. Tal processo leva a um bloqueio dos sítios ativos de crescimento dos seus cristais. Em seguida, os inibidores podem retardar sua taxa de germinação ou de crescimento, favorecendo o aumento da fragilidade estrutural desses cristais e com isso, diminuindo sua capacidade de precipitação do meio (SHEN et al., 2012). 
Ketrane et al. (2009), analisaram por meio de uma medição quantitativa indireta, a potenciometria, a ação de inibidores pertencentes a diferentes classes sob o $\mathrm{CaCO}_{3}$ presente em uma água dura. A variação da temperatura do sistema avaliado levou-os a concluir que apenas os à base de fosfonato apresentaram resultados satisfatórios para inibição desse sal sob quaisquer das condições avaliadas.

O presente trabalho tem como objetivo principal avaliar por meio de um estudo fundamental em batelada o comportamento de um composto fosfonatado sob uma calcita da Islândia $\left(\mathrm{CaCO}_{3}\right)$, variando a temperatura de processo e o tempo de contato entre o sal e o inibidor, de forma a se verificar se esse novo método de análise pode ser empregado com a mesma eficácia dos procedimentos de avaliação indireta citados na literatura.

\section{MATERIAIS E MÉTODOS}

\subsection{Materiais}

A calcita da Islândia empregada nos ensaios foi originaria da coleção didática da Washington School - EUA.

Inicialmente, esse material foi cuidadosamente macerado e em seguida foi realizada uma distribuição do tamanho de suas partículas por meio de um sistema de peneiras. A amostra selecionada para realização dos experimentos em batelada foi submetida a um novo ensaio para que se pudesse confirmar a granulometria padrão de $225 \mu \mathrm{m}$ desse material.

O inibidor de incrustação avaliado nesse estudo, o ácido nitrilotrimetilfosfônico (Figura 1) foi adquirido da Sigma-Aldrich (EUA). Para o preparo de todas as soluções utilizouse a água ultrapura Mili-Q (Millipore, EUA).

A análise das amostras no ICP-OES foi realizada empregando gás Argônio, adquirido da White Martins Praxair Inc. (Brasil) e uma solução padrão de fósforo em meio aquoso de 1000 mg/L da SpecSol (Brasil).
Figura 1 - Estrutura Química do ATMP<smiles>O=P(O)(O)CN(CP(=O)(O)O)CP(=O)(O)O</smiles>

Fonte: www.sigma-aldrich.com

\subsection{Ensaios de Retenção}

Os ensaios de retenção foram realizados em um banho termostático com controle de agitação (QUIMIS, modelo Q226M2), empregando $12 \mathrm{~mL}$ da solução de ATMP e $0,24 \mathrm{~g}$ de mineral.

A obtenção das curvas de retenção $\left(C_{e q}\right.$ - quantidade de soluto presente na fase fluída (mmol/L) em equilíbrio com $q$ - quantidade de soluto retido na fase sólida $(\mathrm{mg} / \mathrm{g})$ ) foi realizada para diferentes condições de operação; cada erlenmeyer contendo uma solução de diferente concentração de ATMP $(0,01 ; 0,05 ; 0,1 ; 0,5 ; 1,0 ; 2,0 ; 3,0 ; 5,0$ e 10,0 $\mathrm{mmol} / \mathrm{L})$.

Ao fim do processo, alíquotas do sobrenadante foram retiradas, centrifugadas em uma microcentrífuga refrigerada (CIENTEC, modelo CT-15000R) por $10 \mathrm{~min}$ a $15000 \mathrm{rpm}$ e armazenadas para posterior análise no ICP-OES, de forma a se determinar a concentração de fósforo após o equilíbrio.

A quantidade de inibidor retido foi calculada por meio de um balanço de massa, sendo a equação descrita a seguir:

$q=\frac{\left(C_{0}-C_{e q}\right) V_{s o l}}{m_{a d s}}$

em que $q$ representa a quantidade de inibidor retido por grama de material $(\mathrm{mg} / \mathrm{g}) ; C_{e q}$ a concentração de inibidor na fase líquida $(\mathrm{mg} / \mathrm{L})$ em equilíbrio; $C_{0}$ a concentração inicial de inibidor na fase líquida $(\mathrm{mg} / \mathrm{L})$; $m_{\text {ads }}$ a massa de calcita (g) e $V_{\text {sol }}$ o volume 
de solução (L) disponível para o contato com o mineral.

\section{RESULTADOS E DISCUSSÃO}

A retenção do ATMP sob a superfície do $\mathrm{CaCO}_{3}$ foi avaliada a partir de ensaios em batelada. A influência da temperatura no processo foi averiguada a partir de ensaios em duas temperaturas: 25 e $70{ }^{\circ} \mathrm{C}$. As mesmas foram selecionadas visando atingir os extremos da mais ampla faixa de temperatura que pudéssemos varrer dentro dos limites dos equipamentos empregados em nossas análises. As curvas obtidas estão expressas na Figura 2.

Figura 2 - Curvas de retenção obtidas para calcita em contato com a solução de ATMP a diferentes temperaturas de processo $\left(\square 25^{\circ} \mathrm{C}\right.$; $\left.\bullet 70^{\circ} \mathrm{C}\right)$ por $48 \mathrm{~h}$

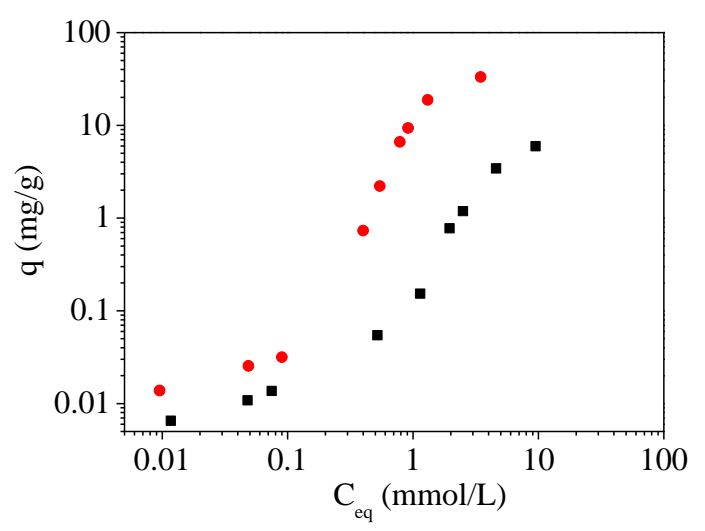

Como podemos verificar na Figura 2, à medida que a temperatura aumenta, tem-se um respectivo acréscimo na quantidade de ácido metilfosfônico retido na superfície da calcita, ou seja, menor será o número de $\mathrm{CaCO}_{3}$ precipitado, pois ao ocorrer a ligação entre esse sal e o inibidor, o cristal de carbonato de cálcio terá sua estrutura danificada, facilitando sua solubilização.

O resultado observado é condizente com o reportado na literatura por método eletroquímico, uma vez que Ketrane et al.
(2009) também constataram que o acréscimo nesse parâmetro acarreta um aumento da taxa de retenção.

Visando analisar a influência do tempo de contato na capacidade de retenção do inibidor sob a superfície da calcita, novos ensaios foram realizados. A Figura 3 traz os resultados obtidos.

Figura 3 - Curvas de retenção obtidas a para calcita ao ser submetida a diferentes tempos de contato com a solução de ATMP/NaCl a $70{ }^{\circ} \mathrm{C}($ $12 \mathrm{~h} ; \bullet 24 \mathrm{~h} ; \Delta 48 \mathrm{~h}$ ).

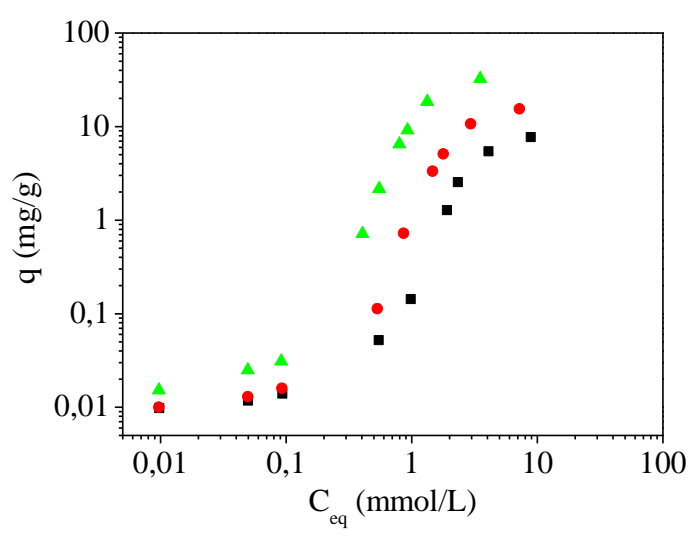

Ketrane et al. (2009) concluiram a partir de seu estudo que o aumento do tempo de contato entre o inibidor e $\mathrm{o}^{\mathrm{CaCO}_{3}}$ não influenciava na capacidade de inibição da incrustação. Entretanto, os resultados apresentados na Figura 3 mostram o contrário, uma variação das condições de equilíbrio com o tempo, visto que a quantidade de inibidor retido na superfície do mineral sofre um acréscimo proporcional ao aumento desse tempo de contato. A discrepância entre os nossos resultados e o dos autores pode ser justificada levando-se em conta que tais autores avaliaram a influência desse fator em um intervalo de tempo muito reduzido (100 min), tempo esse possivelmente insuficiente para completa ação dos efeitos difusivos associados à cinética desse sistema. 
Analisando as curvas apresentadas nas Figuras 2 e 3, podemos visualizar que as mesmas possuem um comportamento similar e a partir dessas pode-se identificar a concentração ótima de inibidor a ser empregada em cada situação, concentração essa que está diretamente relacionada à capacidade máxima de retenção do mineral.

\section{CONCLUSÃO}

Diante dos resultados apresentados neste trabalho, pode-se inferir que o método estático em batelada pode ser empregado para avaliar a eficiência de inibidores de incrustação fosfonatados, podendo ser empregado para obtenção de tais resultados com tamanha precisão quando comparado às técnicas eletroquímicas já empregadas.

Vale ressaltar ainda que nossos gráficos são caracterizados por um ponto ótimo e por isso podem ser usados em outros estudos de forma que se possa comparar a capacidade de inibição entre substâncias pertencentes a diferentes espécies.

\section{REFERÊNCIAS}

SPARROW, E. M. Fluid-to-Fluid Conjugate Heat Transfer for a Vertical Pipe. ASME Journal of Heat Transfer, v.102, p.402-407, 1980.

BELlARDY, J. Well Completion Design. Developments in Petroleum Science, 2009.

FROSTMAN, L. M.; KAN, A. K.; TOMSON, M. B., in: AMJAD, Z. (Ed.). Calcium Phosphates in Biological and Industrial Systems. Kluwer Academic, Boston, MA, p. 493 - 506, 1998.

KETRANE，R.; SAIDANI，B.; GIL，O.; LELEYTER, L.; BARAUD, F. Efficiency of Five Scale Inhibitors on Cal Cium Carbonate
Precipitation from Hard Water: Effect of Temperature and Concentration. Desalination, v. 249, p. 1397 - 1404, 2009

LIN, Y.-P.; SINGER, P. C. Inhibition of Calcite Crystal Growth by Polyphosphates. Water Research, v. 39, p. 4835 - 4843, 2005.

SHEN, Z.; LI, J.; XU, K.; DING, L.; REN, H. The Effect of Synthesized Hydrolyzed Polymaleic Anhydride (HPMA) on the Crystal of Calcium Carbonate. Desalination, v. 284, p. $238-244,2012$. 